Nicola Simmons, BROCK UNIVERSITY,nsimmons@brocku.ca Earle Abrahamson, UNIVERSITY OF EASTLONDON, winedge@hotmail.com Jessica M. Deshler, WEST VIRGINIA UNIVERSITY, deshler@math.wvu.edu Barbara Kensington-Miller, THE UNIVERSITY OF AUCKLAND, b.kensington-miller@auckland.ac.nz

Karen Manarin, MOUNT ROYAL UNIVERSITY, kmanarin@mtroyal.ca Sue Morón-García, UNIVERSITY OF BIRMINGHAM, s.d.morongarcia@bham.ac.uk Carolyn Oliver, UNIVERSITY OF BRITISH COLUMBIA, carolyn@carolynoliver.com Joanna Renc-Roe, CENTRALEUROPEANUNIVERSITY, rencroej@ceu.hu

\title{
Conflicts and Configurations in a Liminal Space: SoTL Scholars' Identity Development
}

\begin{abstract}
Although academic identity has received attention in the literature, there have been few attempts to understand the influence on identity from engagement with the Scholarship of Teaching and Learning (SoTL). In this paper, we (a group of eight scholars from five different countries) describe how our interactions with SoTL have impacted the shaping of our academic identities. We have struggled to define the value, purpose, outcomes, and meanings of being a disciplined SoTL scholar, sometimes in addition to and sometimes in opposition to being a disciplinary scholar. Through analysis of our own 100-word reflective narratives, we identify common conflicts and configurations around our experiences of developing a SoTL identity. We describe how navigating among conflicting identities can lead us into a troublesome but deeply reflective liminal space, prompting profound realizations and the reconstruction of academic identity. Drawing on this notion of liminality helps us to understand our journeys as moving through a necessary and important transformational landscape, and allows us to suggest ways to support those engaging with SoTL to develop an integrative SoTL identity.
\end{abstract}

\section{KEYWORDS}

academic identity, Scholarship of Teaching and Learning (SoTL), liminality, troublesome knowledge

\section{SOTL SCHOLARS' IDENTITY: INTRODUCTION}

An increasingly expansive body of literature explores academic identity development (Åkerlind, 2005; Bath \& Smith, 2004; Clegg, 2008; Fanghanel \& Trowler, 2008; Janke \& Colbeck, 2008; Jawitz, 2007; Land, 2001; Simmons, 2011; Trowler \& Knight, 2000). ${ }^{1}$ There have been, however, few attempts to explore the influence of engagement with the Scholarship of Teaching and Learning (SoTL) on academic identity. In this article, we consider how involvement with SoTL has impacted our various academic identities as 
teachers, academic developers, students, and scholars. We go beyond previous writings describing the process of negotiating a SoTL identity (Huber, 2005; Kelly, Nesbit, \& Oliver, 2012; Tremonte, 2011) to analyse common elements of our experience and to draw on Meyer and Land's (2005) notion of liminality to apply to SoTL identity development. We describe how navigating among conflicting identities can lead us into a troublesome but deeply reflective liminal space, prompting profound realizations and the reconstruction of our academic identities.

As SoTL scholars from different backgrounds, we have reflected individually and collaboratively on how we negotiated, and continue to negotiate, our numerous identities vis-à-vis SoTL. We ask how involvement with SoTL has impacted our various academic identities, what challenges this has presented, and what we have learned that will bear meaning for others. We consider the literature on academic identity before presenting a thematic analysis of our individual reflective narratives regarding SoTL identity development. This suggests a number of similarities in the conflicts and configurations involved in constructing an academic identity for SoTL.

We have struggled to define the value, purpose, outcomes, and meanings of being a disciplined SoTL scholar, sometimes in addition to and sometimes in opposition to being a disciplinary scholar. SoTL has troubled our identities, but has simultaneously led us to new understandings of ourselves. We see this unsettling of identity as inherent to the process of engaging with SoTL and that normalising it as such may be helpful to others. The tensions that arise are to be expected, as is the transformative paradigm shift that can occur as academic identity in SoTL becomes more deeply understood.

\section{ACADEMIC IDENTITY: DISCIPLINED SOTL SCHOLAR VERSUS DISCIPLINARY SCHOLAR}

While academic identity can be defined as the meaning one attaches to roles and tasks required within a particular institutional context, it is often seen as disciplinary identity. The disciplines have been characterized as academic tribes marked by particular ways of thinking and acting (Becher, 1989), and a key task for educators is seen as socialising students into disciplinary norms, thus perpetuating a shared sense of disciplinary identity. This sense of identity can be threatened by tensions between disciplinary scholarship and the interdisciplinary arena of SoTL (Huber, 2005; Tremonte, 2011). SoTL has tried to position itself within the disciplines (Healey 2000; Huber \& Morreale 2002), and certainly disciplines engage in education-focused scholarship. At the same time, SoTL has explicitly situated itself as a cross-disciplinary conversation, a "'trading zone' among the disciplines" (Huber \& Morreale, 2002, p. 19).

Recent theorists have suggested that more fluid metaphors may better represent how academics typically characterize their identity. Brew (2008), for example, suggests that identities are much more permeable than the metaphor of tribes suggests and that academics [re]define themselves as they negotiate among contexts. Brew outlines that such self-reflexive approaches to identity position interdisciplinarity not as "conceptually deviant" (p. 434), but as normal practice whenever disciplinary lines begin to blur. Such approaches allow us to articulate SoTL identities without the language of exceptionalism (Coppola, 2011) or definitions that exclude through tight delineation.

Social identity theory (Tajfel, 2010; Tajfel \& Turner, 1979) reconciles these two positions by suggesting that identity is formed through a dynamic, contextually responsive 
process of mentally assigning ourselves to social groups depending on which categorisation best supports positive self-concept and self-esteem. According to this theory, we hold multiple social identities and will identify with that which is most salient at any given time. Socialisation into a discipline or community of practice (Wenger, 1998) can provide the type of unambiguous, supportive, and highly salient identity scripts on which it is easy for academics to draw. Engagement with SoTL, however, often means these identity scripts are challenged as we negotiate a new language for interdisciplinary communication, navigate alien epistemologies, methodologies, and concepts or take on a whole new way of looking at the world (Kelly, Nesbit, \& Oliver, 2012; Oliver, Nesbit, \& Kelly, 2013). Yet a SoTL identity may also be hard to access because deconstructing one's own teaching, wandering outside the sphere of disciplinary expertise, or operating in conditions in which SoTL is devalued can bring uncertainty and a loss of status and may not immediately fit with how we see ourselves. At the same time, some may find comfortable ways of navigating those tensions.

Social identity theory suggests three possible responses when our identity is challenged (Tajfel, 2010; Tajfel \& Turner 1979). The first response is to abandon it altogether in favour of an identity that carries a higher status and better supports a positive self-concept. For disciplinary scholars engaging with SoTL, this risks severing important links to the home audience. A second response is for members of each discipline to retreat to their group identity and make comparisons with other disciplines that increase their group's esteem. Such discipline-based SoTL groups protect disciplinary turf but perhaps impede the interdisciplinary communication that is so important to SoTL (Weimer, 2006). The third response is to redefine the characteristics of the threatened group. This involves those who engage with SoTL reworking how they see themselves to reconcile disciplinary and SoTL identities. For example, Little and Green (2012) suggest academic developers frequently reinvent themselves in this way, inhabiting "a persisting liminal location which can foster 'positive, creative' possibilities” (p. 214).

\section{TROUBLESOME KNOWLEDGE AND LIMINALITY}

Initially, we felt that threshold concepts would provide a useful framework for our findings. Meyer and Land (2005) describe threshold concepts as discipline-specific "conceptual gateways" (p. 373). Building on Perkins' (1999) description of troublesome knowledge, Meyer and Land argue that "threshold concepts lead not only to transformed thought but to a transfiguration of identity and adoption of an extended discourse" (p. 375). Such concepts bring learners to "the threshold as the entrance into the transformational state of liminality" (p. 380). We felt hard pressed, however, to define exactly what concept was the threshold in our multiple experiences.

What continued to resonate with the group was this notion of liminality. Meyer and Land (2005) contrast liminality with the threshold metaphor, noting that liminality "appears to be a more 'liquid' space, simultaneously transforming and being transformed by the learner as he or she moves through it" (p. 380). The lens of threshold concepts contains the notion that a predetermined path exists - a way through the liminal space to more expert knowledge. Most of us position ourselves as still in this liminal space as we navigate developing our SoTL identities. We confront external tension in terms of our acceptance and position within our discipline-specific scholarship, as explored, for instance, in Huber (2005). This external tension fuels conceptual and affective difficulties 
and calls for us to navigate complex boundaries. A more powerful and often hidden tension is internal; engaging with SoTL leads to troubled knowing. It requires us to develop the capacity to become comfortable being in a nexus of discomfort created by SoTL work.

\section{EXPLORING OUR SOTL IDENTITIES: METHOD}

This paper is based on mini-narratives of a maximum of 100 words written by each author to describe our individual experiences of developing a SoTL identity. We responded to the prompt of writing about moments of critical insight about our SoTL identities, moments of discomfort, or particularly transformational moments. These narratives were written after the authors collaborated, both online and subsequently face-to-face, as a SoTL Scholar Identity writing group, one of the ISSOTL pre-conference international collaborative writing groups in 2012. The participant authors, who self-selected, comprise a range of experiences and background disciplines and roles (see Table 1).

Two authors took the lead on analysing and thematically coding the narratives using a constant comparison method (Glaser \& Strauss, 1967). Initially, all narratives were read as a set for an overview, and then analyzed inductively for patterns of emergent themes (Neuman, 1997) about SoTL identity development as well as individual variations. The analysis focused on identity reconstructions regarding movement into SoTL. Themes were returned to all group members for verification (Lincoln \& Guba, 1985).

Table 1. Author Demographics

\begin{tabular}{|c|c|c|c|c|c|}
\hline & & PRIMARY & SECONDARY & & YEARS \\
\hline & & ACADEMIC & ACADEMIC & DISCIPLINARY & OF SOTL \\
\hline AUTHOR & COUNTRY & ROLE & ROLE & BACKGROUND & ENGAGEMENT \\
\hline Nicola & Canada & $\begin{array}{l}\text { Faculty } \\
\text { member }\end{array}$ & $\begin{array}{l}\text { Academic } \\
\text { Developer }\end{array}$ & $\begin{array}{l}\text { Higher \& Adult } \\
\text { Education }\end{array}$ & 9 \\
\hline Earle & England & $\begin{array}{l}\text { Academic } \\
\text { Developer }\end{array}$ & $\begin{array}{l}\text { Educational } \\
\text { Policy Writer }\end{array}$ & Sport Science & 9 \\
\hline Jessica & U.S. & $\begin{array}{l}\text { Faculty } \\
\text { member }\end{array}$ & $\begin{array}{l}\text { Graduate } \\
\text { Student } \\
\text { Developer }\end{array}$ & Mathematics & 5 \\
\hline Barbara & New Zealand & $\begin{array}{l}\text { Faculty } \\
\text { member }\end{array}$ & $\begin{array}{l}\text { Academic } \\
\text { Developer }\end{array}$ & Mathematics & 2 \\
\hline Karen & Canada & $\begin{array}{l}\text { Faculty } \\
\text { member }\end{array}$ & & English & 5 \\
\hline Sue & England & $\begin{array}{l}\text { Academic } \\
\text { Developer }\end{array}$ & & $\begin{array}{l}\text { Education, } \\
\text { Languages }\end{array}$ & 5 \\
\hline Carolyn & Canada & PhD Candidate & Instructor & Social Work & 3 \\
\hline Joanna & Hungary & $\begin{array}{l}\text { Academic } \\
\text { Developer }\end{array}$ & & Higher Education & 7 \\
\hline
\end{tabular}

\section{LIMINAL IDENTITIES}

Key themes that emerged from the data analysis were intrapersonal conflicts of doubt and insecurity, intrapersonal identity reconfigurations, and the role of the SoTL community in building an alternative identity. In this section we expand on each, providing excerpts from our narratives in support of the themes. We chose not to attribute these excerpts, in light of the need for safety associated with the first two themes. 


\section{Doubt and Insecurity: Intrapersonal Conflicts}

SoTL identity construction can be challenging given the sometimes perceived foreignness of the language, concepts, and methodologies of SoTL. Those of us who are not social scientists perceived a methodological alienation of being asked to do educational or social research:

I was accepted into a SoTL residency program (a multi-day introduction to SoTL), and spent three weeks leading up to the first residency reading books about social science methodology and trying to understand introductory statistics.

These feelings are also present, however, for most of us who are seemingly in SoTL-related disciplines, and may persist even when, to external eyes, we appear quite successful as SoTL scholars:

While I have published in SoTL and presented at SoTL conferences I don't know if I can claim to 'be' SoTL in even a small part of me. I love my SoTL-esque research but I've read the definitions of SoTL a hundred times and I can't see where my interest... fits.

Doing SoTL work means developing different conventions of research and questioning the conventions of our own home disciplines as well as what SoTL is. Whilst these issues may be variously resolved after a time, they point to an ongoing identity struggle as we construe the work we do as SoTL scholars in relation to our disciplinary scholarship.

This has led some of us to write stories of insecurity and risk about entering this unfamiliar territory of SoTL and has generated feelings of being once again a novice, complete with multiple identity crises and self-doubts. One of us noted,

I am still figuring out how SoTL fits my disciplinary identity. . . After 16 years... I'm nearly at a point of having some academic credibility and a $\mathrm{PhD}$ in my discipline. I'm not sure I can face starting again with another discipline and another literature.

Entering SoTL thus requires us to reconstruct our identities, considering both new and established academic selves, often triggering feelings of being an imposter (Brookfield, 1990). This is particularly challenging for those of us who are still developing our sense of belonging in the main academic discipline. One author reflected,

Developing my own academic identity moving from teacher to student and back again, always aware of what I don't know!. . . Following a need to seek meaning and work through misconceptions; others seem less worried.

Many of our stories give voice to continuous strong feelings of self-questioning, discomfort, and risk taking, and even self-denial or hiding this identity in specific disciplinary contexts. For example, one of us reflected,

My fear of identifying as a SoTL scholar permeates my professional role in hiding the fact that I am SoTL-focused when working within a disciplinespecific role. This fear retards my ability to engage positively in good practice and promote the value of good practice. 
Our narratives articulate our experienced difficulty and doubt and reveal the amount of internal work necessary to construct a SoTL scholar out of a (partially) constructed academic self.

\section{Developing SoTL Identity: Intrapersonal Configurations}

There is evidence in all our narratives that meaningful accommodation and assimilation of the conflicting identities occurs over time. This often takes the form of a profound self-realisation, suggesting crossing an identity threshold. For some of us this process happened through a sudden moment of achieving a new understanding of SoTL itself. This enabled our academic or professional self to re-assert itself in the context of SoTL work. For example, one of us mused,
After two sleepless nights at the residency, feeling overwhelmed and inade- quate, I suddenly realized that I didn't have to become a social scientist, that I could use my disciplinary skills .... I read texts and look for pat- terns; I can do that with texts demonstrating student learning.

Such critical moment narratives show the synergetic aspect of SoTL with our own disciplinary identity.

For most of us, the potential for a configuration of a new identity occurs when SoTL work makes possible a meta-analysis of our research activity as scholars. This often means realizing an alternative source of academic/research identity than the discipline itself. One author noted,

While working with academics from all disciplines a critical moment came when I realized that it wasn't the discipline I needed as my research platform, but an overarching theme that would incorporate all my research ideas regardless of discipline.

Our work as SoTL scholars thus moves us into a new, interdisciplinary field of research and practice. Another of us said,

I've been reading and I've understood ... that what makes SoTL stronger is this ability to move across the disciplines ... or apply approaches different to those traditionally used in your discipline.

SoTL becomes understood as an expansive or inclusive form of academic research and academic work, for some, a new way of being an academic. One author described this shift,

I've started to realize that the educational research I do can be described as SoTL ... and that I can continue to develop as a researcher; I need not concern myself with how others might classify my work but with where I think it fits.

The SoTL self-construction allows us to pull together different aspects of our academic identity into a unified whole. For example,

Being engaged in SoTL ... has allowed me to link together various threads that run through my biography - my obsession with higher education itself, some pervasive methodological and thematic orientations, the need to do academic work across disciplinary borders and with real people. 
These moments of self-realisation allow us to take up a new perspective on all of our academic work. This view is apparent in one author's reflection that

As an academic, it is difficult to separate the work that I do from the person that I am. I consider myself a disciplined academic engaged with disciplinary and SoTL scholarship .... Being a SoTL practitioner dictates a position wherein I can continue with scholarship, and embed good practice into a range of papers and topics.

Whether generated by a sudden realisation or over a longer period of self-questioning and analysis, what these narratives show is how SoTL forms a hybrid, fluid, and productive identity, one that allows us to come up with alternative configurations of our educational biography.

\section{The Role of SoTL Community in Building an Alternative Identity: Interpersonal Configurations}

We have all benefited significantly from the support of our alternative academic community of SoTL colleagues as we stepped over the threshold to this new identity formation. This, to different degrees, has allowed us to navigate how we then relate SoTL to our homes in the disciplines. One of us mused,

At the end of a SoTL residency I realize I have found an academic community, but still have to go home to my department, a different sort of community. Three years later, I inhabit both.

SoTL becomes a second home that allows us to maintain a sense of self worth where otherwise we might have faced criticism. Another author found,

On my return to a faculty I found less focus on improving practice than building theory. I continue to juggle: SoTL, they say, is not real research... thank goodness for SoTL colleagues in other disciplines.

The interdisciplinary nature of SoTL may be seen as one of its welcoming aspects:

I also found the interdisciplinary space I enjoyed as an academic developer and in which I most love to work.

Our identity construction builds on our inter-subjective recognition from SoTL colleagues. Indeed for some of us, it was the moment of engaging in collaborative work with other SoTL colleagues that allowed us to resolve some of the internal conflicts over our identity formation. One of us reflected that

Coming back from ISSOTL ... feeling really fired up and feeling more like that SoTL scholar I was unsure I was!

In some cases, these resolutions had the flavour of significant paradigm shifts:

It was during this interaction ... that I slowly became aware of what SoTL does, as opposed to what it is ... the SoTL interaction moved me to a new way of thinking and doing. 
Conversations with other SoTL scholars allowed us to become aware of possibilities for building new identity configurations. Engaging in a SoTL community was experienced as a support to shaping our practices as well as our identities.

For others, SoTL as a community has long been an alternative site of developing mentoring relationships that sustain us as professionals in new and unfamiliar fields of practice in contexts where these fields are not adequately supported, either intellectually or materially. One author explains,

It was through working with SoTL that I became an academic developer, in a place where no one identified as such.... I learnt the milestones of developing a SoTL identity by observing my scholars whilst the SoTL community has been my professional reference point and a source of significant mentors for my own development.

It was this aspect of SoTL as a productive field of self-realisation that allowed integration of SoTL into an academic self through the sense of belonging in a clearly defined community. The ISSOTL conference was seen as a particular support:

\section{Colleagues encouraged attendance at early ISSOTL conferences and here I} found an intellectual home, having always inquired into my teaching.

These realizations point to how SoTL serves as a location for integrating multiple, conflicting, and interdisciplinary areas of academic work.

\section{SWIMMING IN THE LIMINAL SEA}

We recognized from our own experiences and our knowledge of identity development literature that identity construction does not happen in a vacuum within the self but rather in interplay with one's peers and the larger context one inhabits (Lave \& Wenger, 1991). Trowler and Knight (2000), amongst others, outline the process of acclimatization into department cultures, including the challenges of role resolution that occur as one's own approach intersects with the established norms of the department culture (Jawitz, 2007). Peers and their beliefs and values can thus be both supports in the socialization process and hindrances as one accommodates to their approaches.

While our narratives examined the notion of becoming SoTL scholars, one of the challenges is that SoTL as a culture is still constructing itself, and it may be difficult for newcomers to identify what it means to think as a SoTLer. As Jawitz (2007) notes, those who enter an academic field bring their own perspectives, which then influence the cultural norms of that field. In the case of SoTL, which could be said to still be in its adolescence (identity formed, but still challenging what it wants to be when it grows up), this can be both wonderfully supportive, as newcomers can truly add to the crafting of that identity, and also challenging, as it may be doubly difficult to get a strong sense of the cultural norms of engaging with SoTL.

For each of us, construing a SoTL academic identity has proved troublesome in one way or another, giving rise to conflicts, discomfort, risk-taking, and transformative and integrative experiences. This includes one person whose initial entry to SoTL felt seamless; even she has subsequently encountered challenges to academic identity vis-à-vis SoTL work. Seeing academic identity through the lens of troublesome knowledge and liminality helps us to understand our journeys as moving through a necessary and im- 
portant transformational landscape. It alerts us to the possibility of transformative moments or paradigm shifts along the way, although these cannot necessarily be anticipated along a linear path.

Addressing our SoTL identity causes us to recognize that becoming comfortable in our identities may not be our ultimate goal. Indeed, we note that identity is a problematic subject with cognitive and affective dimensions (Kegan, 1982), including not only epistemological issues of knowing but also intrapersonal and interpersonal spheres (Baxter Magolda, 1999), with various personal tensions that must be resolved as individuals move through developmental stages (Kegan, 1982). Our goal is thus to learn to be comfortable in the discomforting spaces we currently inhabit. While our areas of doubt are almost never resolved, we can develop new, hybrid, multiple, or alternative identities that enable us to integrate SoTL into our academic lives. By adopting an integrative identity script, we can redefine ourselves so we neither abandon our pre-SoTL academic identities altogether nor cling to them so closely we miss opportunities for interdisciplinary dialogue and personal transformation.

In the process of redefinition, we are supported by various configurations of a SoTL community conceived as an alternative academic home or support network. The SoTL community makes a SoTL identity more salient by giving it value, reinforcing it, and helping us see how we might use it. As our SoTL identities are not equally valued in all the communities we inhabit, we are creative, self-reflexive, and careful about how we use or share these new and alternative identities, and we look to the broader SoTL community for our SoTL identities to be supported.

There are, of course, limitations to our work. We are but a small group of eight; furthermore, we self-selected to participate in the ISSOTL international writing group on SoTL Scholar Identity. We came to this study, therefore, not as outsider researchers, but rather as academics living the experience of constructing our SoTL identities. Our perspectives reflect both our interests and experiences, and should not be assumed to be shared by all. At the same time, there are indications that the three themes we have identified reflect the experiences of some other scholars engaging with SoTL (Oliver, Nesbit, \& Kelly, 2013). Despite our varied backgrounds, what have been most compelling to us have been the similarities in our experiences along with the extraordinary support we have found amongst our group members as we discussed swimming the liminal sea.

\section{FURTHER THOUGHTS}

Examining academic identity through the lens of troublesome knowledge and liminality points us towards new ways in which the SoTL community can provide support. Land, Cousin, Meyer, and Davies (2005) suggest educators design a carefully sequenced "framework of engagement" offering multiple opportunities to engage recursively with, and gain new ways of thinking about, the troublesome threshold concept. This raises the question of how we can more explicitly structure opportunities for SoTL scholars to consider their academic identity. Whether this be formalised through SoTL curricula or informally in the way we run our conferences, we should perhaps consider expanding opportunities for participants to engage with the question of what it means to be in SoTL. More discussion of the many ways one can be a SoTL scholar may help us to grasp what Land et al. (2005) call the "underlying game" (p. 56).

Land et al. (2005) also suggest acknowledging the extent of pre-liminal variation. 
For example, Savin-Baden (2012) advises that "what occurs for [individuals encountering a threshold] is not just 'variation' but different ways of managing the disjunction being experienced" (p. 163). More research is needed to understand the different identities and aspirations we bring to engagement with SoTL and how these affect the evolution of academic identity. Another area for exploration is how to further develop the considerable capacity of the SoTL community to be a "supportive liminal environment" (Land et al., 2005, p. 58), within which new learning can take place and identity struggles might be safely navigated. Finally, Land et al. discuss the importance of acknowledging the discomfort involved in wrestling with a threshold concept and moving through the liminal space, and of reinforcing the metacognitive capacity to tolerate uncertainty.

\section{LIMINAL SCHOLARS}

When we began discussing our ideas for this paper, we grappled at length with the term "SoTL scholar." While we drew on Boyer's (1990) idea of scholarship of teaching as an important part of academic work, there were also concerns that not everyone in the group was a scholar according to notions of going public (Healey, 2003). If some of us drew on the literature instead of contributing to it, were we practitioners rather than scholars? We have since come to the realisation that the very conversations we had along the way, in and of themselves, made our reflections public to our peers; this paper is an extension of those conversations and an invitation to further conversations. While we acknowledge the limitations of working with personal accounts from our small group of eight, we hope that this paper contributes to understanding aspects of developing a SoTL identity, not least by offering some solidarity to others who are negotiating what it means to be a SoTL scholar. Academic identity in SoTL may certainly be troublesome, but the reward for continuing to wrestle with it can be transformative.

\section{ACKNOWLEDGEMENTS}

We are extraordinarily grateful to our peer reviewers for helping clarify our thinking. Nicola Simmons is a faculty member in Graduate and Undergraduate Studies in Education at Brock University.

Earle Abrahamson is an educational and quality assurance consultant currently working at the University of East London.

Jessica Deshler is an Assistant Professor of Mathematics at West Virginia University where she serves as the Graduate Teaching Assistant Coordinator.

Barbara Kensington-Miller is a senior lecturer in academic development, working in the Centre for Learning and Research in Higher Education at Auckland University.

Karen Manarin is Associate Professor in the Departments of English and General Education at Mount Royal University.

Sue Morón-García is an academic developer who supports engagement with SoTL through a postgraduate certificate in academic practice, University of Birmingham, UK.

Carolyn Oliver is a PhD candidate at the School of Social Work, University of British Columbia. 
Joanna Renc-Roe is a lecturer at the Center For Teaching and Learning at Central European University in Budapest, Hungary.

\section{NOTES}

1. We were privileged to participate in a collaborative international writing group prior to the 2012 ISSOTL conference. We engaged with SoTL debate and discourse, but more importantly, reflective analysis of what SoTL does, and how it moves individuals to tackle new and different directions in teaching and learning research. We are grateful to have had this experience that generated not only this paper, but our ongoing reflections and continuing scholarly partnership.

\section{REFERENCES}

Åkerlind, G. (2005). Academic growth and development: How do university academics experience it? Higher Education: The International Journal of Higher Education Research, 50(1), 1-32.

Bath, D., \& Smith, C. (2004). Academic developers: An academic tribe claiming their territory in higher education. International Journal for Academic Development, 9(1), 9-27.

Baxter Magolda, M. B. (1999). Creating contexts for learning and self-authorship. Nashville, TN: Vanderbilt University Press.

Becher, T. (1989). Academic tribes and territories: Intellectual enquiry and the cultures of disciplines. Buckingham, UK: Society for Research into Higher Education and the Open University Press.

Boyer, E. (1990). Scholarship reconsidered: Priorities of the professoriate. New York, NY: The Carnegie Foundation for the Advancement of Teaching.

Brew, A. (2008). Disciplinary and interdisciplinary affiliations of experienced researchers. Higher Education: The International Journal of Higher Education Research, 56, 423-438.

Brookfield, S. D. (1990) The skillful teacher: On technique, trust, and responsiveness in the classroom. San Francisco, CA: Jossey-Bass.

Clegg, S. (2008). Academic identities under threat? British Educational Research Journal: Journal of the British Education Research Association, 34(3), 329-345.

Coppola, B. P. (2011). Making your case: Ten questions for departments and individuals building an argument for work in discipline-centered education. International Journal for the Scholarship of Teaching and Learning, 5(1).

Fanghanel, J., \& Trowler, P. (2008). Exploring academic identities and practices in a competitive enhancement context: A UK-based case study. The European Journal of Education: Research, Development and Policy, 43(3), 301-313.

Glaser, B. G., \& Strauss, A. L. (1967). The discovery of grounded theory. Hawthorne, NY: Aldine. Healey, M. (2000). Developing the scholarship of teaching in higher education: A disciplinebased approach. Higher Education Research \& Development: Journal of the Higher Education Research and Development Society of Australasia, 19(2), 169-189.

Healey, M. (2003). The scholarship of teaching: Issues around an evolving concept. Journal on Excellence in College Teaching, 14(1/2), 5-26. 
Huber, M. T. (2005). Balancing acts: The scholarship of teaching and learning in academic careers. Sterling, VA: Stylus.

Huber, M. T., \& Morreale, S. (Eds.). (2002). Disciplinary styles in the scholarship of teaching and learning. Menlo Park, CA: Carnegie Foundation for the Advancement of Teaching.

Janke, E. M., \& Colbeck, C. L. (2008). Lost in translation: Learning professional roles through the situated curriculum. New Directions for Teaching and Learning, 113, 57-68.

Jawitz, J. (2007). New academics negotiating communities of practice: Learning to swim with the big fish. Teaching in Higher Education, 12(2), 187-197.

Kegan, R. (1982). The evolving self: Problem and process in human development. Cambridge, MA: Harvard University Press.

Kelly, N., Nesbit, S., \& Oliver, C. (2012). A difficult journey: Transitioning from STEM to SOTL. International Journal for the Scholarship of Teaching and Learning, 6(1).

Land, R. (2001). Agency, context and change in academic development. International Journal for Academic Development, 6(1), 4-20.

Land, R., Cousin, G., Meyer, J. H. F., \& Davies, P. (2005). Threshold concepts and troublesome knowledge (3): Implications for course design and evaluation. In C. Rust (Ed.), Improving student learning diversity and inclusivity (pp. 412-424). Oxford: Oxford Centre for Staff and Learning Development.

Lave, J., \& Wenger, E. (1991). Situated learning: Legitimate peripheral participation. Cambridge: Cambridge University Press.

Lincoln, Y. S., \& Guba, E. G. (1985). Naturalistic inquiry. Beverly Hills, CA: Sage.

Little, D., \& Green, D. A. (2012). Betwixt and between: Academic developers in the margins. International Journal for Academic Development, 17(3), 203-215.

Meyer, J. H. F., \& Land, R. (2005). Threshold concepts and troublesome knowledge (2): Epistemological considerations and a conceptual framework for teaching and learning. Higher Education:The International Journal of Higher Education Research, 49, 373-388.

Neuman, W.L. (1997). Social research methods: Qualitative and quantitative approaches (3 $3^{\text {rd }}$ ed.). Needham Heights, MA: Allyn and Bacon.

Oliver, C., Nesbit, S., \& Kelly, N. (2013). Dissolving dualisms: How two positivists engaged with non-positivist qualitative methodology. International Journal of Qualitative Methods, 12, 180-194.

Perkins, D. (1999). The many faces of constructivism. Educational Leadership, 57(3), 6-11.

Savin-Baden, M. (2012). Disjunction as a form of troublesome knowledge in problem-based learning. In J. H. F. Meyer, \& R. Land (Eds.), Overcoming barriers to student understanding: Threshold concepts and troublesome knowledge. (pp. 160-172). New York, NY: Routledge.

Simmons, N. (2011). Caught with their constructs down? New academics' development as teachers. International Journal for Academic Development, 16(3), 229-241.

Tajfel, H. (Ed.). (2010). Social identity and intergroup relations ( $2^{\text {nd }}$ ed., vol. 7). Cambridge: Cambridge University Press.

Tajfel, H., \& Turner, J. C. (1979). An integrative theory of intergroup conflict. In W. G. Austin 
\& S. Worchel (Eds.), The social psychology of intergroup relations (pp. 33-47). Monterey, CA: Brooks-Cole.

Tremonte, C. M. (2011). Window shopping: Fashioning a scholarship of interdisciplinary teaching and learning. International Journal for the Scholarship of Teaching and Learning, 5(1), 1-10.

Trowler, P., \& Knight, P. T. (2000). Coming to know in higher education: Theorising faculty entry to new work contexts. Higher Education Research \& Development: Journal of the Higher Education Research and Development Society of Australasia, 19(1), 27-42.

Weimer, M. (2006). Enhancing scholarly work on teaching and learning: Professional literature that makes a difference. San Francisco, CA: Jossey-Bass.

Wenger, E. (1998). Communities of practice. Learning, meaning and identity. Cambridge: Cambridge University Press. 